\title{
Reactions between an Insect Picornavirus and Naturally Occurring IgM Antibodies in Several Mammalian Species
}

\author{
J. F. LONGWORTH, J. S. ROBERTSON \& T. W. TINSLEY
}

Natural Environment Research Council, Unit of Invertebrate Virology, University of Oxford

\author{
D. J. ROWLANDS \& F. BROWN
}

Animal Virus Research Institute, Pirbright, Surrey

\section{Domestic and wild animals have IgM antibodies which react with insect viruses. Infection by agents sharing common antigens with the insect viruses could account for this phenomenon.}

THE use of viruses to control insect pests is attractive because of the undoubted economic advantage and apparent high degree of specificity. Insect viruses are claimed to have a restricted host range and there are no records of transmission to animals outside the class Insecta. Here, however, we describe serological reactions between a picornavirus which infects Gonometa podocarpi (Lepidoptera: Lasiocampidae) and naturally occurring antibodies in several mammalian species, which suggests that the animals may have been exposed to the virus or a serologically related antigen.

\section{Serological Relationships}

Gonometa virus is morphologically similar to the small RNA viruses infecting vertebrates and also resembles them in several physico-chemical properties; for example, it contains $37 \%$ single-stranded RNA, the protein moiety comprises four polypeptides with molecular weights ranging from 36,500 to 12,000 and the virus has a buoyant density of $1.35 \mathrm{~g} \mathrm{~cm}^{3}$ in caesium chloride ${ }^{1}$. Tests were therefore made to determine whether any serological relationships existed between the Gonometa virus and vertebrate picornaviruses. Bovine enterovirus VG-5-27 ${ }^{2}$, porcine enterovirus Italian $1 / 66^{3}$, encephalomyocarditis virus, vesicular exanthema virus and several serotypes of foot-and-mouth disease virus, each of which gave a precipitation line with its homologous antiserum in immunodiffusion tests, did not react with Gonometa virus antisera which had been produced in rabbits and guinea-pigs and gave a homologous reaction at a dilution of 1/16. Nor were precipitation lines obtained between the Gonometa virus and hyperimmune guinea-pig antisera to the vertebrate viruses listed above.

The chance observation, however, that sera from pigs infected with the Italian $1 / 66$ virus produced a precipitation line with purified Gonometa virus prompted a more detailed examination of this reaction. When sera from pigs infected with foot-and-mouth disease were reacted with purified Gonometa virus, a precipitation line appeared in each test. This line gave a pattern of non-identity with the line produced by the same serum and foot-and-mouth disease virus particles but it did fuse with that produced by Gonometa virus and its homologous rabbit antiserum (Fig. 1). Moreover, preinoculation sera from all the animals subsequently infected with foot-and-mouth disease virus also gave a precipitation line with Gonometa virus and all the six sera we examined were strongly positive.

\section{IgM Antibody}

The substance in the pig serum giving this reaction was stable at $56^{\circ} \mathrm{C}$, but precipitating activity was destroyed when the serum was treated overnight with $0.1 \mathrm{M}$ 2-mercaptoethanol. This suggested that the reaction involved IgM antibody and the following confirmatory evidence has been obtained.

Serum from a pig infected 7 days previously with foot-andmouth disease virus was centrifuged for $16 \mathrm{~h}$ at $90,000 \mathrm{~g}$ in a $15-25 \%$ sucrose gradient. Fractions from the gradient were concentrated with half-saturated ammonium sulphate and tested with Gonometa virus and foot-and-mouth disease virus. The fractions from the $19 \mathrm{~S}$ region of the gradient gave a precipitation line with each virus (Fig. 2). Serum from an animal infected some weeks previously was fractionated similarly. The fractions from the $19 \mathrm{~S}$ region of the gradient with this serum gave a line with Gonometa virus and a weak reaction with foot-and-mouth disease virus, whereas the fractions from the $7 \mathrm{~S}$ region gave a reaction with foot-andmouth disease virus only.

Serum samples from a pig infected with foot-and-mouth disease virus were electrophoresed in agarose and the separated

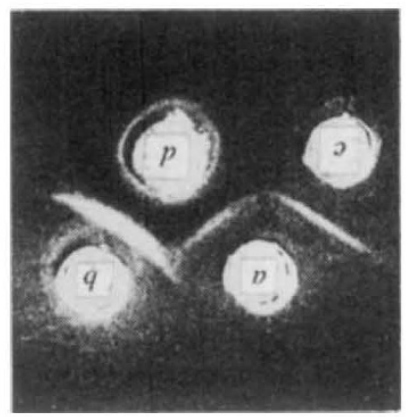

Fig. 1 Immunodiffusion test with Gonometa virus (a), foot-andmouth disease virus $(b)$, rabbit antiserum to Gonometa virus (c) and serum from a pig infected with foot-and-mouth disease virus $(d)$. The test shows the identity of the lines produced with Gonometa virus and the two sera and the non-identity of the lines produced with the pig serum and the two viruses. 

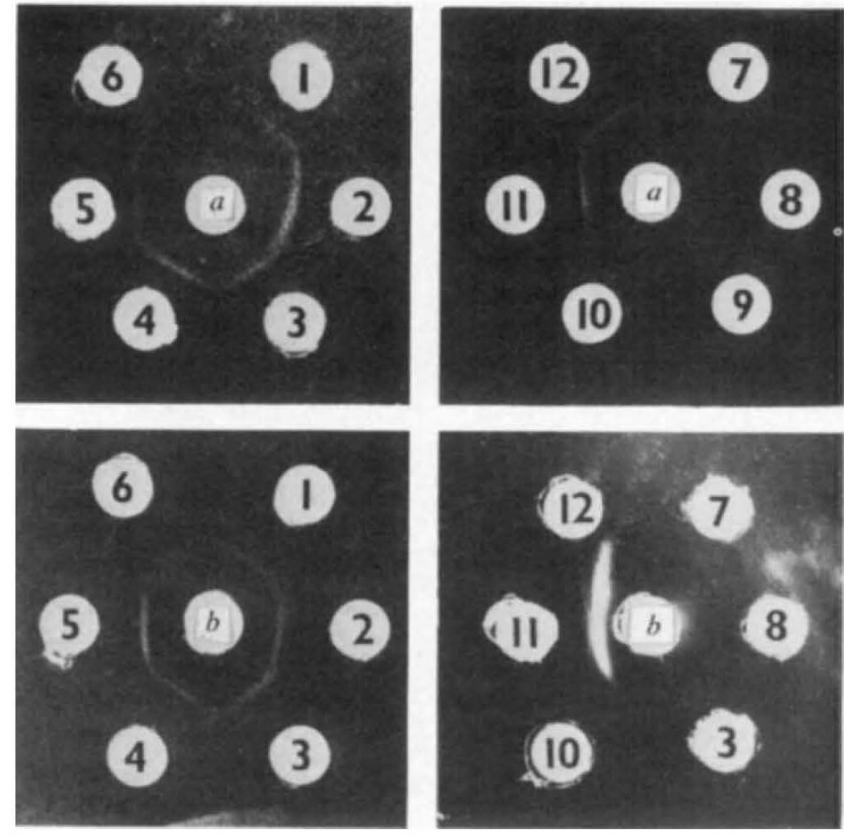

Fig. 2 Immunodiffusion test of the fractions prepared by sucrose gradient centrifugation of pig serum obtained seven days after infection with foot-and-mouth disease virus, using Gonometa virus $(a)$ and the homologous foot-and-mouth disease virus $(b)$ as antigens. 1-10 refer to the sucrose gradient fractions, numbered from the bottom of the tube. Unfractionated pig serum and rabbit antiserum to Gonometa virus are at positions 11 and 12.

proteins then allowed to diffuse towards channels containing Gonometa virus or foot-and-mouth disease virus. Serum taken 7 days post-infection gave a precipitation line with each virus at the position of IgM. Serum collected 18 days postinfection gave a line with Gonometa virus only at the IgM position, whereas the reaction with foot-and-mouth disease virus was mainly at the position of IgG.

Mixtures of Gonometa virus and purified IgM antibody from pig serum were examined in the electron microscope. Complexes were observed which were similar to those obtained with foot-and-mouth disease virus and the homologous IgM antibody ${ }^{4}$ and with Gonometa virus and its homologous IgM antibody. The complexes of Gonometa virus and IgM antibody from pig serum showed attachment of antibody molecules at regular intervals on the virus surface (Fig. 3). In contrast, complexes of Gonometa virus with the homologous IgG antibody showed attachment of the antibody molecules over the entire surface of the virus.

The Gonometa virus did not react with the IgG fraction prepared by DEAE-cellulose chromatography of serum from pigs infected with foot-and-mouth disease virus. This IgG antibody preparation gave a precipitation line with the homologous virus.

In all the tests described, the Gonometa virus particles had been purified by sucrose gradient and caesium chloride centrifugation. The supernatant from the infected insect homogenate, from which the virus had been pelleted at $80,000 \mathrm{~g}$, did not give a reaction with the pig serum. This indicated that soluble insect proteins did not react non-specifically with any components of the pig serum. Further, a recently isolated virus from Darna trima (Lepidoptera: Limacodidae) (J. S. R. and J. F. L., unpublished data), obtained from Sabah (formerly Borneo), which is not related serologically to the Gonometa virus, also gave a precipitation line with the pig serum and this did not fuse with the line produced by Gonometa virus (Fig. 4); thus, these reactions are not identical. These observations suggest that the reaction between Gonometa virus and pig serum is specific.

Because natural antibodies of the IgM class are found in the sera of a wide range of animals, pig serum giving a strong
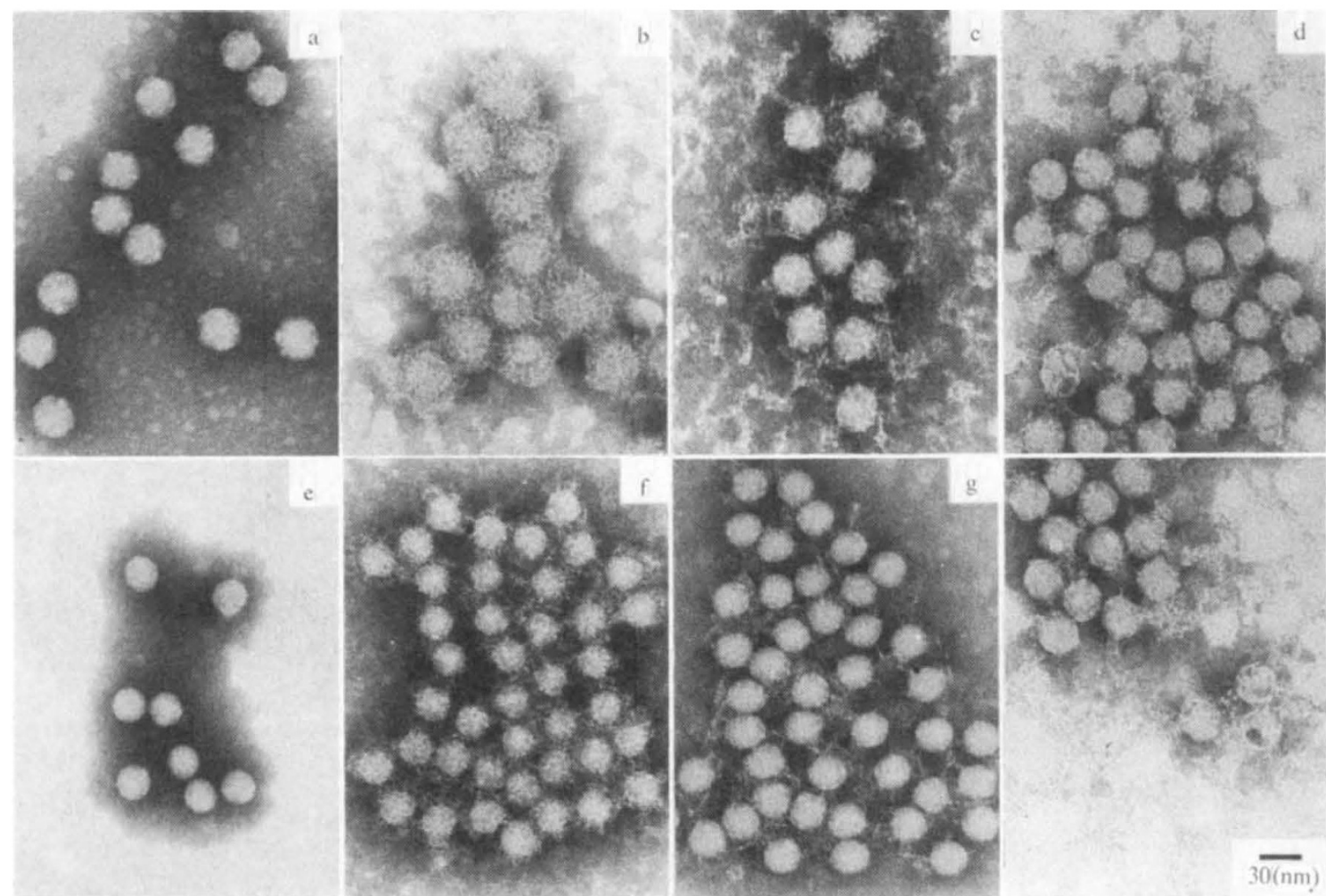

Fig. 3 Electron micrographs of complexes of Gonometa virus with the specific IgG and IgM antibodies and with the IgM fraction of pig serum compared with those obtained with foot-and-mouth disease virus and the specific IgG and IgM antibodies: $a$, Gonometa virus alone; $b$, plus IgG; $c$, plus IgM; $d$, plus IgM fraction from pig serum; $e$, FMDV alone; $f$, plus IgG; $g$, plus IgM. 


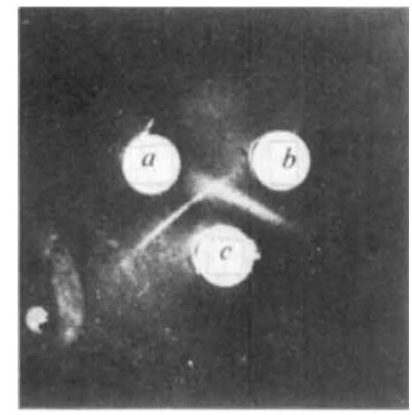

Fig. 4 Immunodiffusion test of Gonometa virus (a) and Darna trima virus $(b)$ with pig serum $(c)$, showing the lack of identity in the two reactions.

reaction with Gonometa virus was tested with a range of bacterial antigens which have been shown to react in some cases with IgM from animals not experimentally exposed to the antigens. Only one of ten antigens, namely Salmonella minnesota glycolipid, gave a precipitation reaction with the pig serum and this line did not fuse with that produced by Gonometa virus. Furthermore, as antigens on sheep red blood cells react with sera from other species, pig serum which had been absorbed with sheep red blood cells was tested with Gonometa and Darna trima viruses. The absorbed serum gave a precipitation line with each virus.

\section{Reactions with Other Species}

The sera of several other species have also been tested for their reactivity with Gonometa virus. Reactions were obtained with sera from cattle $(10 / 10)$, sheep $(4 / 6)$, horses $(4 / 6)$, dogs $(1 / 6)$ and three species of deer (10/10). The intensity of the reaction varied considerably in individual animals of the same species, for example, some undiluted sera gave only a faint reaction whereas reactions were occasionally obtained with sera diluted $1 / 8$. The precipitation lines obtained with the different species fused, providing further evidence for the specificity of the reaction. No reactions were obtained with sera from guinea-pigs and rabbits which had been reared for laboratory purposes, nor with wild rabbit sera. It was significant that sera obtained from gnotobiotic pigs (6 animals) and cattle (6 animals) did not react with Gonometa virus.

These observations raise some important questions, particularly as to the stimulus which produces IgM antibody in these animal species. It is possible that the reaction occurred because the animals had previously been exposed to Gonometa virus. As the Gonometa virus was isolated from an insect species which is indigenous to East Africa and has not been recorded elsewhere, it seems unlikely that this virus induced the response. The class Insecta contains some $75 \%$ of the known animal species, however, of which only a small number have been examined for the viruses they may harbour, and it is quite feasible that the Gonometa virus or serologically related viruses occur in other parts of the world. Indeed, in some instances, close serological relationships have been demonstrated between viruses isolated from quite unrelated insects whose habitats are widely separated geographically ${ }^{5,6}$. It is possible therefore that there are viruses either of invertebrate or of vertebrate origin which are widely prevalent in the United Kingdom which share common antigens with the Gonometa virus.

It is not clear why the response involves only $\operatorname{IgM}$ antibodies but this could be explained on the basis of a low but frequently repeated stimulus. There are several reports in the literature of the presence of virus-neutralizing substances in the sera of animal species not regarded as natural hosts. Cattle sera from Sierra Leone, Ghana, Uganda, Sudan and Kenya contained neutralizing substances, probably antibodies, against yellow fever virus ${ }^{7}$. This was also true, however, of $3 / 40$ cattle sera from India and 1/153 from England and France, where exposure to infection with yellow fever virus could be ruled out. The phenomenon of neutralizing substances to polio virus in cows has been reviewed ${ }^{8}$; serum from $75-90 \%$ of cattle over three years of age neutralized not only type 2 polio virus but also type 1 and occasionally type 3 . The neutralizing substances were usually present in low titre but possessed all the properties of antibody in human sera, including a predominant association with the gamma globulin fraction. In calves of four to six months of age, neutralizing substances were rarely found. A significant feature of this work was that calves without neutralizing antibody could not be infected with a virulent strain of polio virus, irrespective of portal of entry, and moreover failed to develop antibodies to it. Sabin 8 concluded that "in cattle, at least, the antibody appearing in low titre with advancing age was probably the result of infection with another agent possessing antigenic groups that are related to those of poliomyelitis virus". A more recent observation is the presence in pigs in Japan of high levels of neutralizing antibody to Nodamura virus ${ }^{9}$, which has been tentatively classified as a picornavirus $^{10}$. Neutralizing antibody was also found in $1 / 54$ herons and egrets ${ }^{9}$, and it was concluded that pigs were the likely source of Nodamura virus, since they were frequently bitten by Culex tritaeniorhyncus, the mosquito from which the virus was first isolated. The nature of the neutralizing antibodies has not been determined, so it is not known if IgG or IgM is involved.

These observations with Gonometa and Darna trima viruses have implications relating to the control of insect pest populations by the deliberate release of viruses. While it is probably true that most insect viruses exhibit a high degree of host specificity and thus have great potential in biological control programmes, it is obviously desirable that sound experimental data should be available to check this specificity. It seems unlikely that the antibody to the two insect viruses resulted from infection and multiplication of similar agents in the mammalian hosts. The IgM response implies repeated low level exposure to the antigen concerned which must therefore be widely distributed in the environment. The close relationship of these antigens to the two viruses suggests the existence of viruses in some host population, possibly arthropod, in the areas from which our serum samples were drawn. The ubiquity of these agents and the apparent regularity with which they can reach mammalian hosts stress the risks which might arise from the deliberate release of virus to control insect pest populations, should the viruses used exhibit wider host specificity than expected.

We thank Mr C. J. Smale for the electron micrographs; Miss Janet Dewdney, Beecham Research Laboratories, Surrey, for supplying the bacterial antigens; and the following for providing the various sera: Professor W. Plowright, Royal Veterinary College, London; Dr J. Ross, Pest Infestation Laboratory, Surrey; and Miss J. Crick, Mr R. Burrows and Drs E. P. J. Gibbs and G. N. Mowat, Animal Virus Research Institute, Pirbright.

\section{Received November 20, 1972.}

1 Longworth, J. F., Payne, C. C., and Macleod, R., J. Gen. Virol. (in the press).

${ }^{2}$ Martin, S. J., Johnston, M. D., and Clements, J. B., J. Gen. Virol., 7, 103 (1970).

${ }^{3}$ Nardelli, L., Lodetti, E., Gualandi, G. L., Burrows, R., Goodridge, D., Brown, F., and Cartwright, B., Nature, 219, 1275 (1968).

4 Brown, F., and Smale, C. J., J. Gen. Virol., 7, 115 (1970).

5 Day, M. F., and Mercer, E. H., Aust. J. Biol. Sci., 17, 892 (1964).

6 Cunningham, J. C., and Tinsley, T. W., J. Gen. Virol., 3, 1 (1968),

${ }^{7}$ McCallum, F. O., and Findlay, G. M., Trans. Roy. Soc. Trop. Med. and Hyg., 31, 199 (1937).

${ }^{8}$ Sabin, A. B., in Poliomyelitis, WHO Monograph No. 26, 297 (1955).

9 Scherer, W. F., Verna, J. E., and Richter, G. W., Amer. J. Trop. Med. and Hyg., 17, 120 (1968).

10 Murphy, F. A., Scherer, W. F., Harrison, A. K., Dunne, H. W., and Gary, G. W., Virology, 40, 1008 (1970). 